\title{
Mesiodistal Crown Dimensions of Permanent Teeth in Bangladeshi Population
}

\author{
Saeed Hossain Khan ${ }^{1}$, Gazi Shamim Hassan², Tanzila Rafique ${ }^{3}$, Md. Nazmul Hasan', Md.Sharif Hossain Russell ${ }^{5}$ \\ ${ }^{1}$ FCPS Student, ${ }^{2}$ Chairman \& Associate Professor, ${ }^{3}$ Medical Officer, Dept. of Orthodontics, Bangabandhu Sheikh Mujib Medical University, \\ ${ }^{4}$ Assistant Professor, Dept. of Orthodontics \& Dentofacial Orthopedics, Update Dental College, ${ }^{5}$ Research Assistant, Dept. of Conservative \\ Dentistry \& Endodontics, Bangabandhu Sheikh Mujib Medical University
}

\begin{abstract}
:
Background: Variation in tooth size is influenced by genetic and environmental factors. Several studies have reported tooth size variation between and within different racial groups. In order to improve the quality of dental care available, there is a great need for data on the mesiodistal crown dimensions of the individual teeth of Bangladeshi population. Objectives: To find nominative data on the mesiodistal crown dimensions of permanent teeth in Bangladeshi population and to compare the findings with those reported in other populations. Methods: This observational study was done from January, 2008 to June, 2010 in the Department of Orthodontics, Faculty of Dentistry, Bangabandhu Sheikh Mujib Medical University. A total of 244 Bangladeshi subjects (77 males and 167 females), aged 7 - 36 years (mean 18.3 years) with no age limit who attended at the above mentioned place for treatment were included in the study. Main outcome measure was mesiodistal crown dimension of each tooth class of permanent dentition. Mesiodistal crown dimensions were measured from dental casts of the permanent teeth. Results: Males had significantly larger teeth than females for maxillary central incisors $(\mathrm{p}<0.05)$ and for the mandibular second premolars ( $<<0.001$ ). In both sexes, the maxillary lateral incisors showed the greatest variability [coefficient of variation (CV) 10.7\%] and the maxillary canines the least (CV 6.9\%) in mesiodistal crown dimension. Mandibular canines displayed greater sexual dimorphism in mesiodistal crown size than in any other tooth classes. Comparisons of the mesiodistal crown dimensions between population groups showed that Bangladeshis have tooth sizes close to those of North Indians, Icelanders and Jordanians but larger than those of North American Whites. Conclusions: From this study, a standard for the mesiodistal crown dimensions of permanent dentition of Bangladeshi males and females are obtained.
\end{abstract}

Key Words: Crown dimension, Mesio-Distal width, Permanent dentition.

[BSMMU J 2011; 4(2): 81-87]

\section{Introduction:}

Variation in tooth size is influenced by genetic and environmental factors ${ }^{1}$. Several studies have reported tooth size variation between and within different racial groups. Keene ${ }^{2}$ reported racial differences in tooth sizes among the American Negroes and their Caucasian counterparts in caries-free naval recruits. Turner and Richardson also observed significant differences in mesiodistal tooth width in Kenyan and Irish populations. In another related study Bishara ${ }^{3}$ compared the mesio-distal and bucco-lingual crown dimensions of the permanent teeth in three populations from Egypt, Mexico and the United States. The results from this study indicated

Address for correspondence: Dr. Tanzila Rafique, Department of Orthodontics, Faculty of Dentistry, Bangabandhu Sheikh Mujib Medical University, Dhaka, e-mail: tanzila_rafique@yahoo.com, Contact : 01713-409165. statistically significant differences in the mesio-distal dimension among the three populations. Apart from racial differences, the other factors associated with tooth size variability are gender ${ }^{3,4,5}$, environment ${ }^{6}$, hereditary factors, bilateral differences and secular changes ${ }^{7}$.

The genetic basis for this variation is best explained by a polygenic model of inheritance. Lundstrdm ${ }^{7}$, compared 97 pairs of like-sex monozygotic and dizygotic twins and found a stronger correlation in mesiodistal tooth size between monozygotic twins. He concluded that tooth size is determined to a large extent by genetic factors. Tooth size variations have been reported between various ethnic populations like North American Caucasians, Negroes, Mongoloids, Dominicans, Egyptians, Mexicans, Nigerians, British, Peruvians, etc. Racial variations have also been observed in the Eskimos, Bushmen, Lapps, Australian aboriginals and the Bantu races of Africa. Such differences 
could have implication in the application of diagnostic criteria derived from specific populations, as in prediction equations used to estimate mesiodistal crown dimensions of unerupted permanent teeth. Without information about the size of individual teeth and groups of teeth, it is difficult for a clinician to make a diagnosis and plan treatment and to carry out a plan of therapy.

Very few information are available about mesiodistal crown dimensions of permanent dentition in Bangladeshi population. Jahan $^{8}$ studied mesiodistal crown dimensions of permanent dentition of 60 (30 males and 30 females) Bangladeshi subjects with Class-I skeletal pattern. Ali ${ }^{9}$ studied Bolton anterior tooth size discrepancies among different malocclusion groups. He measured the mesiodistal crown dimensions of permanent incisors and canines and used them for calculation of anterior Bolton ratio. But these studies could not provide sufficient data on mesiodistal crown dimension of permanent dentition in Bangladeshi population. In order to improve the quality of dental care available, there is a great need for data on the mesiodistal crown dimensions of the individual permanent teeth of Bangladeshi population. The main purpose of the study was to assess whether the diagnostic criteria derived from the mesiodistal crown dimensions of permanent dentition of other populations can be used interchangeably in Bangladeshi population.

\section{Methods:}

This Observational study was done from January, 2008 to June, 2010 in the Department of Orthodontics, Faculty of Dentistry, Bangabandhu Sheikh Mujib Medical University. Morphologically normal all permanent teeth of both jaws from right second premolar to left second premolar were the study population. Casts with intact mesiodistal diameter of crown of permanent teeth, not affected by any attrition, caries, or restorations, no history of previous orthodontic treatment, proximal stripping or serious health problems were the inclusion criteria. Casts with gross dental abnormalities, apparent loss of tooth substance due to attrition or restorations affecting the mesiodistal diameter of the crown were excluded. A total of 244 Bangladeshi subjects meeting the above enrollment criteria attended at the above mentioned place for treatment were included in the study. Main outcome measure was mesiodistal crown dimension of each tooth class of permanent dentition.

Mesiodistal crown dimensions were measured from dental casts of the permanent teeth. Impressions were made of the selected sample using irreversible hydrocolloid (alginate) impression material for both maxillary and mandibular arches. Impressions were poured immediately in dental stone. Then the study models were prepared. The dental casts measured in this investigation were not treated with soap or otherwise polished. The accuracy of plaster casts fabricated from alginate impressions as a representation of actual tooth size was investigated by Hunter and Priest ${ }^{10}$ method. Hunter and Priest concluded that measurements made on dental casts are more reliable than those made directly in the mouth. The greatest mesiodistal dimension from anatomic mesial contact point to anatomic distal contact point of each tooth was taken to the nearest $0.1 \mathrm{~mm}$ by means of pointed calipers. For assessment of error in the recorded mesiodistal crown dimensions of permanent dentition, the data collection procedure was repeated in one dental cast of every five dental casts included. Then the second findings were matched with the first recorded findings. There were negligible differences between the two successive findings, which increases the authenticity of the collected data. A slide calipers with a vernier scale to read value of nearest up to $0.10 \mathrm{~mm}$ was used to measure the tooth size. The tips of the calipers were grounded to a point in order to facilitate the greatest degree of accuracy.

Statistical analysis was performed using computer software Statistical Package for Social Sciences (SPSS) version 18. The descriptive statistics used were frequency mean and standard deviation. Comparisons between the groups were made by unpaired t-test as the data presented in this were continuous in nature. Level of significance was set at 0.05 and p-value $<0.05$ was considered significant.

\section{Results:}

Of the 244 patients, 167 (68.4\%) were female and 77(31.6\%) were male. Age of the male patients ranged from 8-32 years (Mean 18.3 \pm SD 5.9) and in female ranged from 7-36 years (Mean 18.3 \pm SD 5.5) (Table-1).

Table-I

Demographic characteristic of patients

\begin{tabular}{lccccc}
\hline Gender & \multicolumn{5}{c}{ Age (yrs) } \\
\cline { 2 - 6 } & Frequency (\%) & Mean & SD & Minimum & Maximum \\
\hline Male & $77(31.6)$ & 18.29 & 5.9 & 8 & 32 \\
Female & $167(68.4)$ & 18.30 & 5.5 & 7 & 36 \\
\hline Total & $244(100.0)$ & 18.30 & 5.6 & 7 & 36 \\
\hline
\end{tabular}


The data on mesiodistal crown dimensions of the permanent maxillary and mandibular teeth of the Bangladeshi population studied are summarized in Table II and III respectively. The differences between the mean mesiodistal dimension of any individual tooth on the rightand left-hand sides ranged from 0.01 to $0.15 \mathrm{~mm}$. The mean mesiodistal crown dimensions of the permanent dentition of males were larger than that of females for each type of tooth in the maxillary and mandibular arches.
Analysis showed that all teeth in males, with the exception of the lower central incisors and upper lateral incisors, have significantly greater mesiodistal crown dimensions than those in females (from $\mathrm{p}<0.05$ for the upper central incisors to $\mathrm{p}<$ 0.001 for the lower second premolars). The largest sexual dimorphism in mesiodistal crown dimension was exhibited by the mandibular canines $(0.46 \mathrm{~mm})$ with the mandibular second premolars next in order of difference $(0.40 \mathrm{~mm})$.

Table-II

Mesiodistal crown dimensions of maxillary permanent dentition of Bangladeshi population

\begin{tabular}{|c|c|c|c|c|c|c|c|c|c|}
\hline $\begin{array}{l}\text { No of } \\
\text { Tooth }\end{array}$ & Gender & $\begin{array}{c}\text { Side } \\
\text { involved }\end{array}$ & $\begin{array}{c}n \\
(\mathrm{~mm})\end{array}$ & $\begin{array}{l}\text { Mean } \\
(\mathrm{mm})\end{array}$ & $\begin{array}{c}\mathrm{SD} \\
(\mathrm{mm})\end{array}$ & $\begin{array}{l}\text { SEM } \\
(\mathrm{mm})\end{array}$ & Range & $\begin{array}{l}\mathrm{CV} \\
(\%)\end{array}$ & $\begin{array}{c}\text { Overall } \\
\text { mean }(\mathrm{mm})\end{array}$ \\
\hline \multirow{7}{*}{ CI } & \multirow{3}{*}{ M } & $\mathrm{R}$ & 75 & 9.10 & 0.71 & 0.082 & $7-10.5$ & 7.80 & \multirow{3}{*}{9.11} \\
\hline & & & & & & & & & \\
\hline & & $\mathrm{L}$ & 76 & 9.11 & 0.68 & 0.078 & 7-10.5 & 7.45 & \\
\hline & \multirow{4}{*}{$\mathrm{F}$} & $\mathrm{R}$ & 166 & 8.75 & 0.66 & 0.051 & $6.5-10.5$ & 7.54 & \multirow{3}{*}{8.73} \\
\hline & & & & & & & & & \\
\hline & & $\mathrm{L}$ & 165 & 8.70 & 0.63 & 0.049 & 7-10.5 & 7.24 & \\
\hline & & $\mathrm{R}$ & 74 & 7.48 & 0.81 & 0.095 & $5-9.5$ & 10.83 & \multirow{3}{*}{7.41} \\
\hline \multirow{5}{*}{ LI } & \multirow[t]{2}{*}{$\mathrm{M}$} & & & & & & & & \\
\hline & & $\mathrm{L}$ & 73 & 7.33 & 0.79 & 0.092 & $5-9.0$ & 10.78 & \\
\hline & \multirow{4}{*}{$\mathrm{F}$} & $\mathrm{R}$ & 162 & 7.09 & 0.77 & 0.061 & $4.5-9$ & 10.86 & \multirow{3}{*}{7.06} \\
\hline & & & & & & & & & \\
\hline & & $\mathrm{L}$ & 159 & 7.03 & 0.74 & 0.059 & $5-9.0$ & 10.52 & \\
\hline \multirow{7}{*}{ C } & & $\mathrm{R}$ & 74 & 8.25 & 0.55 & 0.063 & 7-9.5 & 6.67 & \multirow{3}{*}{8.23} \\
\hline & \multirow[t]{2}{*}{ M } & & & & & & & & \\
\hline & & $\mathrm{L}$ & 75 & 8.21 & 0.59 & 0.068 & $7-9.5$ & 7.19 & \\
\hline & \multirow{4}{*}{$\mathrm{F}$} & $\mathrm{R}$ & 153 & 7.94 & 0.56 & 0.045 & $6-9.5$ & 7.05 & \multirow{3}{*}{7.89} \\
\hline & & & & & & & & & \\
\hline & & $\mathrm{L}$ & 154 & 7.85 & 0.53 & 0.043 & $6.5-9$ & 6.75 & \\
\hline & & $\mathrm{R}$ & 73 & 7.51 & 0.51 & 0.059 & 6.5-8.5 & 6.79 & \multirow{3}{*}{7.45} \\
\hline \multirow{5}{*}{$\mathrm{PM}_{1}$} & \multirow[t]{2}{*}{$\mathrm{M}$} & & & & & & & & \\
\hline & & $\mathrm{L}$ & 72 & 7.38 & 0.55 & 0.065 & 6-9 & 7.45 & \\
\hline & \multirow{4}{*}{$\mathrm{F}$} & $\mathrm{R}$ & 159 & 7.23 & 0.51 & 0.040 & $6-8.5$ & 6.77 & \multirow{3}{*}{7.20} \\
\hline & & & & & & & & & \\
\hline & & $\mathrm{L}$ & $156 \quad 7.17$ & 0.51 & 0.041 & $6-8.5$ & 7.11 & & \\
\hline \multirow{6}{*}{$\mathrm{PM}_{2}$} & & $\mathrm{R}$ & 72 & 7.23 & 0.47 & 0.055 & $6-8$ & 6.50 & \multirow{3}{*}{7.22} \\
\hline & \multirow[t]{2}{*}{ M } & & & & & & & & \\
\hline & & $\mathrm{L}$ & 73 & 7.22 & 0.55 & 0.065 & $6-8.5$ & 7.62 & \\
\hline & \multirow{3}{*}{$\mathrm{F}$} & $\mathrm{R}$ & 157 & 6.92 & 0.48 & 0.038 & $5.5-8$ & 6.94 & \multirow{3}{*}{6.90} \\
\hline & & & & & & & & & \\
\hline & & $\mathrm{L}$ & 158 & 6.87 & 0.49 & 0.039 & $5.5-8.5$ & 7.13 & \\
\hline
\end{tabular}

$\mathrm{CI}=$ Central Incisor, $\mathrm{LI}=$ Lateral Incisor, $\mathrm{C}=$ Canine, $\mathrm{PM}_{1}=$ First Premolar, $\mathrm{PM}_{2}=$ Second Premolar.

$\mathrm{SD}=$ Standard deviation, $\mathrm{SE}_{\mathrm{M}}=$ Standard error of mean, $\mathrm{CV}=$ Coefficient of variance, Overall mean = Combined mean of right and left hand sides. 
The mean mesiodistal crown dimension of the maxillary canines was greater than that of the mandibular canines, with an average of $0.88 \mathrm{~mm}$ in males and $1.00 \mathrm{~mm}$ in females. In both sexes the upper first premolars were wider than the upper second premolars, averaging $0.27 \mathrm{~mm}$. In contrast, the lower second premolars were wider than the first premolars $(0.1 \mathrm{~mm})$. In the mandible, the lateral incisors were wider than the central incisors, by an average dimension of $0.57 \mathrm{~mm}$ in males and $0.59 \mathrm{~mm}$ in females. In the maxillary arch, the mean mesiodistal crown dimension of the central incisors was larger than that of the lateral incisors. The mean mesiodistal crown dimension of the first premolars was larger than that of the second premolars. In the mandibular arch, the mean mesiodistal crown dimension of the central incisors was less than that of the lateral incisors. The mean mesiodistal crown dimension of the first premolars was less than that of the second premolars.

In both males and females, the SD and coefficient of variation (CV $=100 \times \mathrm{SD} / \mathrm{Mean}$ ) of tooth size measurement showed that variability differed between individual teeth, with the maxillary lateral incisors showing the greatest variability $(10.7 \%)$, the lower central incisors the next greatest (8.3\%), and the maxillary canine the least (6.9\%). Only slight variability was observed by sex.

Table-III

Mesiodistal crown dimensions of mandibular permanent dentition of Bangladeshi population

\begin{tabular}{|c|c|c|c|c|c|c|c|c|c|}
\hline $\begin{array}{l}\text { No of } \\
\text { Tooth }\end{array}$ & Gender & $\begin{array}{c}\text { Side } \\
\text { involved }\end{array}$ & $n$ & $\begin{array}{l}\text { Mean } \\
(\mathrm{mm})\end{array}$ & $\begin{array}{c}\text { SD } \\
(\mathrm{mm})\end{array}$ & $\begin{array}{l}\text { SEM } \\
(\mathrm{mm})\end{array}$ & $\begin{array}{l}\text { Range } \\
\text { (mm) }\end{array}$ & $\begin{array}{l}\mathrm{CV} \\
(\%)\end{array}$ & $\begin{array}{c}\text { Overall } \\
\text { mean }(\mathrm{mm})\end{array}$ \\
\hline \multirow{4}{*}{ CI } & \multirow{2}{*}{ M } & $\bar{R}$ & 77 & 5.81 & 0.49 & 0.056 & $4.5-7$ & 8.43 & \multirow{2}{*}{5.80} \\
\hline & & $\mathrm{L}$ & 77 & 5.79 & 0.45 & 0.051 & $4.5-6.5$ & .77 & \\
\hline & \multirow{2}{*}{$\mathrm{F}$} & $\mathrm{R}$ & 166 & 5.63 & 0.49 & 0.038 & $4.2-7$ & 8.70 & \multirow{2}{*}{5.66} \\
\hline & & $\mathrm{L}$ & 166 & 5.68 & 0.47 & 0.036 & $4.5-7.0$ & 8.27 & \\
\hline \multirow{4}{*}{ LI } & \multirow{2}{*}{ M } & $\mathrm{R}$ & 75 & 6.35 & 0.56 & 0.064 & 5-7.5 & 8.82 & \multirow{2}{*}{6.37} \\
\hline & & L & 76 & 6.40 & 0.51 & 0.059 & $5.5-7.5$ & 7.97 & \\
\hline & \multirow{2}{*}{$\mathrm{F}$} & $\mathrm{R}$ & 159 & 6.14 & 0.47 & 0.037 & $5-7$ & 7.65 & \multirow{2}{*}{6.25} \\
\hline & & L & 158 & 6.16 & 0.49 & 0.038 & 5-7 & 7.95 & \\
\hline \multirow{4}{*}{ C } & \multirow{2}{*}{ M } & $\mathrm{R}$ & 73 & 7.38 & 0.56 & 0.065 & 6-8.5 & 7.59 & \multirow{2}{*}{7.35} \\
\hline & & $\mathrm{L}$ & 72 & 7.32 & 0.55 & 0.063 & 6-8.5 & 7.51 & \\
\hline & \multirow{2}{*}{$\mathrm{F}$} & $\mathrm{R}$ & 160 & 6.88 & 0.47 & 0.038 & $5.5-8.5$ & 6.83 & \multirow{2}{*}{6.89} \\
\hline & & $\mathrm{L}$ & 159 & 6.89 & 0.48 & 0.038 & 5.5-8 & 6.97 & \\
\hline \multirow{4}{*}{ PM1 } & \multirow{2}{*}{ M } & $\mathrm{R}$ & 73 & 7.48 & 0.54 & 0.064 & $6.5-9$ & 7.22 & \multirow{2}{*}{7.43} \\
\hline & & $\mathrm{L}$ & 72 & 7.39 & 0.56 & 0.066 & 6-8.5 & 7.58 & \\
\hline & \multirow{2}{*}{$\mathrm{F}$} & $\mathrm{R}$ & 160 & 7.10 & 0.56 & 0.044 & $5.5-8.5$ & 7.89 & \multirow{2}{*}{7.12} \\
\hline & & $\mathrm{L}$ & 159 & 7.15 & 0.52 & 0.041 & 6-8.5 & 7.27 & \\
\hline \multirow{4}{*}{ PM2 } & \multirow{2}{*}{ M } & $\mathrm{R}$ & 73 & 7.54 & 0.62 & 0.073 & $6.5-10$ & 8.22 & \multirow{2}{*}{$\begin{array}{l}7.53 \\
8.24\end{array}$} \\
\hline & & & $\mathrm{L}$ & 72 & 7.52 & 0.62 & 0.074 & 6-9.5 & \\
\hline & \multirow{2}{*}{ F } & $\mathrm{R}$ & 155 & 7.11 & 0.51 & 0.041 & 6-8.5 & 7.17 & \multirow{2}{*}{7.13} \\
\hline & & $\mathrm{L}$ & 158 & 7.15 & 0.54 & 0.043 & 6-8.6 & 7.55 & \\
\hline
\end{tabular}

CI =Central Incisor, LI =Lateral Incisor, C = Canine, PM1= First Premolar, PM2= Second Premolar.

$\mathrm{SD}=$ Standard deviation, $\mathrm{SEM}=$ Standard error of mean, $\mathrm{CV}=$ Coefficient of variance, Overall mean = Combined mean of right and left hand sides. 
Table-IV

Comparison of mesiodistal crown dimension of maxillary permanent dentition between males and females

\begin{tabular}{llcc}
\hline Types of Tooth & Gender & Mean & p-value \\
\hline Maxillary Right & Male & 9.10 & $0.01<\mathrm{p}<0.05$ \\
Central Incisor & Female & 8.75 & \\
Maxillary Left & Male & 9.11 & $0.001<\mathrm{p}<0.01$ \\
Central Incisor & Female & 8.70 & \\
Maxillary Right & Male & 7.48 & $0.05<\mathrm{p}<0.1$ \\
Lateral Incisor & Female & 7.09 & \\
Maxillary Left & Male & 7.33 & $0.1<\mathrm{p}<0.5$ \\
Lateral Incisor & Female & 7.03 & \\
Maxillary Right & Male & 8.25 & $0.01<\mathrm{p}<0.05$ \\
Canine & Female & 7.94 & \\
Maxillary Left & Male & 8.21 & $0.001<\mathrm{p}<0.01$ \\
Canine & Female & 7.85 & \\
Maxillary Right & Male & 7.51 & $0.001<\mathrm{p}<0.01$ \\
First Premolar & Female & 7.23 & \\
Maxillary Left & Male & 7.38 & $0.1<\mathrm{p}<0.5$ \\
First Premolar & Female & 7.17 & \\
Maxillary Right & Male & 7.23 & $0.001<\mathrm{p}<0.01$ \\
Second Premolar & Female & 6.92 & \\
Maxillary Left & Male & 7.22 & $\mathrm{p}<0.001$ \\
Second Premolar & Female & 6.87 & \\
\hline
\end{tabular}

$* \mathrm{P}<0.05=$ significant, $\mathrm{P}>0.05=$ not significant.
Table-V

Comparison of mesiodistal crown dimension of mandibular permanent dentition between males and females

\begin{tabular}{llcc}
\hline No. of Tooth & Gender & Mean & $\mathrm{p}$-value \\
\hline Mandibular Right & Male & 5.81 & $0.1<\mathrm{p}<0.5$ \\
Central Incisor & Female & 5.63 & \\
Mandibular Left & Male & 5.79 & $0.1<\mathrm{p}<0.5$ \\
Central Incisor & Female & 5.68 & \\
Mandibular Right & Male & 6.35 & $0.001<\mathrm{p}<0.01$ \\
Lateral Incisor & Female & 6.14 & \\
Mandibular Left & Male & 6.40 & $0.001<\mathrm{p}<0.01$ \\
Lateral Incisor & Female & 6.16 & \\
Mandibular Right & Male & 7.38 & $\mathrm{p}<0.001$ \\
Canine & Female & 6.88 & \\
Mandibular Left & Male & 7.32 & $\mathrm{p}<0.001$ \\
Canine & Female & 6.89 & \\
Mandibular Right & Male & 7.48 & $0.001<\mathrm{p}<0.01$ \\
First Premolar & Female & 7.10 & \\
Mandibular Left & Male & 7.39 & $0.01<\mathrm{p}<0.05$ \\
First Premolar & Female & 7.15 & \\
Mandibular Right & Male & 7.54 & $\mathrm{p}<0.001$ \\
Second Premolar & Female & 7.11 & \\
Mandibular Left & Male & 7.52 & $\mathrm{p}<0.001$ \\
Second Premolar & Female & 7.15 & \\
\hline & & & \\
& &
\end{tabular}

$* \mathrm{P}<0.05$ = significant, $\mathrm{P}>0.05=$ not significant .

Table-VI

Comparison of mesiodistal crown dimension of maxillary dentition in Bangladeshi population with those reported in other populations

\begin{tabular}{|c|c|c|c|c|c|c|c|}
\hline No of & Gender & Bangladeshi & North & North & Jordanian & American & Icelanders \\
\hline Tooth & & Indian & $\begin{array}{l}\text { American } \\
\text { Whites }\end{array}$ & & Negroes & & \\
\hline & $\mathrm{M}$ & 9.11 & 9.05 & 8.74 & 8.94 & 9.12 & 8.99 \\
\hline \multicolumn{8}{|l|}{ CI } \\
\hline & $\mathrm{F}$ & 8.73 & 8.62 & 8.40 & 8.63 & 8.72 & 8.75 \\
\hline & M & 7.41 & 7.07 & 6.64 & 6.93 & 7.26 & 6.95 \\
\hline \multicolumn{8}{|l|}{ L } \\
\hline & F & 7.06 & 6.95 & 6.47 & 6.70 & 7.08 & 6.83 \\
\hline & M & 8.23 & 8.16 & 7.95 & 8.01 & 8.19 & 8.14 \\
\hline \multicolumn{8}{|l|}{ C } \\
\hline & F & 7.89 & 7.86 & 7.53 & 7.62 & 7.74 & 7.79 \\
\hline & M & 7.45 & 7.35 & 7.01 & 7.20 & 7.66 & 7.22 \\
\hline \multicolumn{8}{|l|}{ PM1 } \\
\hline & F & 7.20 & 7.20 & 6.85 & 7.03 & 7.37 & 7.07 \\
\hline & M & 7.22 & 7.10 & 6.82 & 7.00 & 7.25 & 6.89 \\
\hline \multicolumn{8}{|l|}{ PM2 } \\
\hline & $\mathrm{F}$ & 6.90 & 6.76 & 6.62 & 6.82 & 6.94 & 6.84 \\
\hline
\end{tabular}


Table-VII

Comparison of mesiodistal crown dimension of mandibular dentition in Bangladeshi population with other populations

\begin{tabular}{|c|c|c|c|c|c|c|c|}
\hline$\overline{\text { No of }}$ & Gender & Bangladeshi & North & North & Jordanian & American & Icelanders \\
\hline Tooth & & Indian & $\begin{array}{l}\text { American } \\
\text { Whites }\end{array}$ & & Negroes & & \\
\hline & $\bar{M}$ & 5.80 & 5.68 & 5.42 & 5.63 & 5.53 & 5.59 \\
\hline \multicolumn{8}{|l|}{$\mathrm{CI}$} \\
\hline & $\mathrm{F}$ & 5.66 & 5.55 & 5.25 & 5.54 & 5.38 & 5.48 \\
\hline & M & 6.37 & 6.31 & 5.95 & 6.26 & 6.13 & 6.20 \\
\hline \multicolumn{8}{|l|}{ L } \\
\hline & F & 6.15 & 5.98 & 5.78 & 6.07 & 5.99 & 6.02 \\
\hline & M & 7.35 & 7.26 & 6.96 & 7.02 & 7.37 & 7.13 \\
\hline \multicolumn{8}{|l|}{ C } \\
\hline & $\mathrm{F}$ & 6.89 & 6.88 & 6.47 & 6.67 & 6.86 & 6.80 \\
\hline & M & 7.43 & 7.42 & 7.07 & 7.37 & 7.76 & 7.30 \\
\hline \multicolumn{8}{|l|}{ PM1 } \\
\hline & $\mathrm{F}$ & 7.12 & 7.02 & 6.87 & 7.03 & 7.41 & 7.12 \\
\hline & M & 7.53 & 7.50 & 7.29 & 7.46 & 7.85 & 7.45 \\
\hline \multicolumn{8}{|l|}{ PM2 } \\
\hline & $\mathrm{F}$ & 7.13 & 7.17 & 7.02 & 7.20 & 7.61 & 7.27 \\
\hline
\end{tabular}

\section{Discussion:}

In the present study, the mean age is 18.3 years and age range is $7-36$ years (table I). These findings support the statement that orthodontic treatment is usually sought in the early stage of life ${ }^{11-12}$.

The differences between the mean mesiodistal dimension of any individual tooth on the right- and left-hand sides were very small and ranged from 0.01 to $0.15 \mathrm{~mm}$. These findings indicate that right- or left side measurements, for both sexes, could be taken to represent mesiodistal crown dimensions in this population. These findings are in agreement with those reported in other population groups $^{13}$, but contradicting those of Lundstoum ${ }^{7}$, who found a definite difference between left and right tooth measurements.

Harper ${ }^{14}$ provides evidence that the right-left differences between homologous teeth are smaller than the differences between the teeth of monozygotic twins, suggesting that the side differences can be attributed to environmental influences. According to Garn ${ }^{15}$, intra-individual variations in crown size and similarities between isomers and antimeres might be derived from specific intrauterine events during odontogenesis and less from genetic effects.

The mean mesiodistal crown dimensions of the permanent dentition of Bangladeshi males were larger than that of Bangladeshi females for each type of tooth in the maxillary and mandibular arches (tables II and III) which contrasts with the previous findings on Bangladeshi population where there was no significant difference between males and females ${ }^{8}$. Both males and females exhibited a similar pattern of tooth size (tables II \& III).

Comparisons of data pertaining to Bangladeshi population were made with those of North Indian ${ }^{11}$, North American White ${ }^{3}$, American Negroes ${ }^{16}$ and Jordanian populations ${ }^{17}$. The mesiodistal crown dimensions of permanent teeth of Bangladeshi population are in close proximity to those of American Negroes ${ }^{16}$ and North Indian population ${ }^{11}$.

The mean difference in mesiodistal crown dimensions maxillary teeth between Bangladeshi population and American Negroes is $0.08 \mathrm{~mm}$. In case of North Indian and Jordanian population mean differences are $0.11 \mathrm{~mm}$ and $0.23 \mathrm{~mm}$ respectively. North American Whites showed smaller mesiodistal crown dimensions than Bangladeshi population. In case of North American Whites the mean difference is $0.42 \mathrm{~mm}$.

\section{Conclusion:}

From the findings, it could be concluded that:

1. the differences between antimeres were of small magnitude and were not clinically significant.

2. male- female comparisons indicate the presence of sexual dimorphism although they exhibited a similar pattern of tooth size. Mandibular canines and second premolars of both arches were significantly larger in males than in females. No significant differences were present between males and female in the mesiodistal crown dimensions of mandibular central incisors and maxillary lateral incisors. 
3. A higher variability was found in the maxillary lateral incisor as compared to other teeth. This tooth should be examined carefully to exclude any major size and shape discrepancy.

4. Mesiodistal crown dimensions of Bangladeshi population are fairly comparable to other populations for each arch and side of teeth.

Therefore, the diagnostic criteria for these teeth derived from one population could interchangeably be used for other population.

\section{References:}

1. Bailit HL. Dental variation among populations: an anthropologic view. Dent Clinc North Am; 1975.19:125-39

2. Keene H J Mesiodistal crown diameters of permanent teeth in male American Negroes. Am J Orthod .1979;76: 95-99.

3. Bishara SE, Jakobsen JR, Abdallah EM, Garcia AF. Comparisons of mesio-distal and bucco-lingual crown dimensions of the permanent teeth in three populations from Egypt, Mexico and the United States. Am J Orthod \& Dentofac Orthoped. 1989;96:416-22.

4. Ghose LJ, Baghdady VS. Analysis of the dentition: mesiodistal crown diameters of permanent teeth. J Dent Res. 1979;58: 1047-54

5. Lysell L, Myrberg N. Mesiodistal tooth size in the deciduous and permanent dentitions. Eur J Orthod. 1982;4:113-22.

6. Guagliando MF. Tooth crown size differences between age groups: a possible new indicator of stress in skeletal samples. Am J Phys Anthrop. 1982; 58:383-9.
7. Lundstrom, A. Tooth Size and Occlusion in Twins. 1948;S. Karger, New York. Martin

8. Jahan H, Hossain MZ. Tooth size and arch dimension in uncrowded versus crowded class- I malocclusion. Bd J Ortho \& Dentofac Orthoped, 2011; 2:37-38.

9. Ali MW, Hossain MZ. A study on Bolton anterior tooth size discrepancies among different malocclusion groups. Bd J Ortho \& Dentofac Orthoped, 2011; 2:1-4.

10. Hunter WS, Priest WR. Errors and discrepancies in measurement of tooth size. J Dent Res.1960;39:405-14.

11. Singh SP and Goyal A. Mesiodistal crown dimensions of the permanent dentition in North Indian children, $J$ Ind Soc Pedod Prev Dent 2006:192-6.

12. Otuyemi OD, Noar JH. A comparison of crown size dimensions of the permanent teeth in a Nigerian and a British population. Eur J Orthod; 1996;186:23-28.

13. Moorrees CFA. The Dentition of the Growing Child, Journal of Dental Research. 1963;42 : 1490-1502

14. Harper C. A comparison of medieval and modern dentitions. Eur J Orthod 1994;16:163-73

15. Garn SM, Lewis AB. Sex difference in tooth size. J Dent Res; 1964; 43:306

16. Richardson ER, Malharta SK. Mesiodistal crown dimension of the permanent dentition of American Negroes. Am J Orthod; 1975;68:157-64

17. Hattab FN, Al-khateeb S and Sultan I. Mesiodistal crown diameter of permanent teeth in Jordanians. Archs Oral Biol 1996;41;641-5. 